\title{
FUNCTIONAL DISORDERS
}

\section{FUNCTIONAL WEAKNESS STUDY IN YOUNG ADULTS}

Incidence, demographic and clinical characteristics of 107 cases $(79 \%$ female, mean age 39 years) with functional weakness of $<2$ years duration compared to 46 controls with neurological weakness $(83 \%$ female, median age 39 years, duration 11 months) were studied at the University of Edinburgh, UK. The incidence was estimated at 3.9/100,000/year for patients over age 16 years. Socioeconomic status was similar in the two groups. Cases with functional weakness had more physical disability, especially pain, than controls. They had a higher frequency of psychiatric disorders (major depression, anxiety disorder, panic disorder, and somatization disorder). They were less likely to agree that stress was a possible cause of symptoms, and twice as likely as controls to report that they were not working because of their symptoms. Hemiparesis was the most common presentation of functional weakness, in 63\% cases; monoparesis occurred in $16 \%$. There was no preponderance of left-sided symptoms. Positive physical signs included La belle indifference (3\%), collapsing weakness (70\%), Hoover' sign $(56 \%)$, midline split (19\%), decreased vibration (39\%), and decreased temperature sensation (24\%). (Stone J, Warlow C, Sharpe M. The symptom of functional weakness: a controlled study of 107 patients. Brain May 2010;133:1537-1551). (Respond: Dr Jon Stone, Department Clinical Neurosciences, Western General Hospital, Edinburgh, EH4 2XU, UK; E-mail: jon.stone@ed.ac.uk).

COMMENT. Alternative terms for functional weakness include conversion disorder or dissociative motor disorder, psychogenic or non-organic paralysis. The term functional weakness was used to describe the specific symptom and to avoid terms suggestive of etiology. Patients were all adults, and the incidence among children is higher, especially in primary care and orthopedics. Children attending a psychiatric clinic with conversion disorder may have dissociative disorders, emotional and sexual abuse, physical neglect, and other psychiatric comorbidities. (Sar V et al. Am J Psychiatry 2004;161(12):2271-2276). In 52 children admitted to a pediatric teaching hospital with conversion disorder over a 10-year period, the disorder was rare below 8 years of age and

girls outnumbered boys three to one. Gait disturbance was the main complaint in 36 children. Pain was present in 40 (77\%) children, a frequency similar to the above study in adults. At discharge, $32(62 \%)$ were completely recovered or had appreciably improved. A core group was difficult to diagnose and showed little response to treatment. (GrattanSmith P et al. Arch Dis Child 1988;63(4):408-414).

\section{SEIZURE DISORDERS}

\section{UK MULTICENTER RANDOMIZED TRIAL OF HORMONAL TREATMENTS VS VIGABATRIN FOR INFANTILE SPASMS}

The UK Infantile Spasms Multicenter Study previously showed that seizure control after 14 days and development at 14 months are better following hormonal 
treatments (prednisolone or tetracosactide depot) than following vigabatrin (Lux AL et al. Lancet 2004;364:1773-1776). At 4-year follow-up, 9 of 107 enrolled infants had died and 77 were tested for level of development, using the Vineland Adaptive Behavior Scales (VABS), and for seizure control by questionnaire. The median VABS scores were 60 for 39 children allocated hormonal treatment and 50 for 38 allocated vigabatrin $(\mathrm{p}=0.91)$. For children with spasms with no identified etiology, VABS scores were 96 for 21 allocated hormonal treatment, and 63 for the 16 allocated vigabatrin $(\mathrm{p}=0.033)$. For all 77 infants, development and epilepsy outcomes were not significantly different between the two treatment groups at 4-year follow-up. In patients with no identifiable etiology, development was better at both 14 months and 4 years in those allocated hormonal treatment. (Darke K, Edwards SW, Hancock E, et al. Developmental and epilepsy outcomes at age 4 years in the UKISS trial comparing hormonal treatments to vigabatrin for infantile spasms: a multi-centre randomized trial. Arch Dis Child May 2010;95:382386). (Respond: Dr Finbar O'Callaghan, Bristol Royal Hospital for Children. Upper Maudlin St, Bristol BS2 8BJ, UK; E-mail: finbar.ocallaghan@bristol.ac.uk).

COMMENT. A review of the earlier report of the UKISS with a primary outcome of cessation of spasms on days 13 and 14 (Lux et al. Lancet 2004;364:1773-8) found the minimum doses used were vigabatrin $100 \mathrm{mg} / \mathrm{kg} /$ daily $(\mathrm{n}=52)$, oral prednisolone $40 \mathrm{mg}$ day $(n=30)$ or intramuscular tetracosactide depot $0.5 \mathrm{mg}(40 \mathrm{IU})(\mathrm{n}=25)$ on alternate days. Complete seizure control was obtained in $40(73 \%)$ on hormonal treatments (prednisolone $21(70 \%)$, tetracosactide $19(76 \%)$ ) and $28(54 \%)$ on vigabatrin $(\mathrm{p}=0.043)$. Adverse events were reported in $30(55 \%)$ of 55 infants on hormonal treatments and 28 $(54 \%)$ of 52 on vigabatrin. Cessation of spasms occurred more often in infants on hormonal treatment than those given vigabatrin. Adverse events were common with both treatments. The subsequent studies show that hormonal treatment and vigabatrin are equally effective in control of infantile spasms with proven etiology, but for spasms with no identifiable cause, hormonal treatment is preferred.

\section{VITAMIN D INSUFFICIENCY IN CHILDREN WITH EPILEPSY}

Prevalence and risk factors for vitamin D insufficiency among 78 children with epilepsy, aged 3-17 years, treated September 2008-March 2009, were evaluated in a study at the University of Michigan, Ann Arbor, MI. Sex ratio M:F was 41:59; 81\% of European origin; mean age 11.64 years. Low levels of 25 -hydroxyvitamin D $(<20 \mathrm{ng} / \mathrm{ml})$ were found in $25 \%$ of the children and normal levels $(>32 \mathrm{ng} / \mathrm{ml}$ ) occurred in only $25 \%$. Girls and children with elevated body mass index were at increased risk for low 25hydroxyvitamin D. Newer less potent enzyme-inducing antiepileptic drug use (lamotrigine, levetiracetam, oxcarbazepine, gabapentin, topiramate, vigabatrin, zonisamide) was not associated with altered risk compared with older enzyme-inducing drugs (carbamazepine, phenobarbital, phenytoin). The risk was higher for those with localization-related partial epilepsy but these patients had higher body mass index. (Shellhaas RA, Barks AK, Joshi SM. Prevalence and risk factors for vitamin D insufficiency among children with epilepsy. Pediatr Neurol June 2010;42:422-426). (Respond: Dr Shellhaas, L3215 Women's Hospital, 1500 E Medical Center Drive, SPC 5203, Ann Arbor, MI 48109; E-mail: shellhaa@med.umich.edu). 